\title{
TOPOCHEMICAL ASPECTS OF THE CATALYTIC ACTIVITY OF OXIDE SURFACES
}

\author{
G. PARRAVANO \\ Department of Chemical and Metallurgical Engineering, University of Michigan, \\ Ann Arbor, Michigan, U.S.A.
}

Received 26 July 1968

The possibility that orientation relationships between adsorbate and substrate play an important role in adsorption and surface catalysis is analyzed and discussed in analogy with the known topochemistry of solid state reactions. The consequences of crystal chemical accord between adsorbate and bulk phase upon the kinetics of surface processes are examined. These ideas are exemplified by discussing experimental results on the rate of several surface reactions $-\mathrm{O}_{2}$ adsorption and desorption, $\mathrm{H}_{2} \mathrm{O}_{2}$ and $\mathrm{N}_{2} \mathrm{O}$ decomposition, ${ }^{14} \mathrm{CO}_{2}+\mathrm{CO}$ exchange reaction and $\mathrm{H}_{2}+\mathrm{D}_{2}$ exchange reaction - catalyzed by cobalt ferrite samples. By varying the $\mathrm{Co} / \mathrm{Fe}$ ratio different distributions of cations and cation vacancies among crystal sites are possible. This fact has a profound and characteristic influence upon the rate of all the reactions studied. This is taken as evidence that a close crystal chemical accord between the defect distributions in the adsorption layer and in the substrate must be present during the course of the catalytic reactions.

The theoretical and the experimental methods discussed in the paper extend the concept of the so-called geometrical factor in heterogeneous catalysis to cover both crystalline and chemical requirements and it leads to a unified view of concepts derived from geometrical and electrical properties of solids. Finally, it points to the importance of topochemical relations in determining the catalytic reactivity of solid surfaces. 